J. Lake Sci. (湖泊科学) , 2016, 28(5): 982-993

DOI 10. 18307/2016. 0507

(c) 2016 by Journal of Lake Sciences

\title{
$1973-2013$ 年红碱淖水域水质变化及驱动力分析
}

\author{
赵 宁,马 超*, 杨亚莉 \\ （河南理工大学矿山空间信息国家测绘地理信息局重点实验室,焦作 454000）
}

\begin{abstract}
摘 要: 对 1973-2013 年 8 期 Landsat MSS、TM、ETM ${ }^{+} 、$ OLI 影像进行了辐射定标、大气校正、辐射归一化和波段运算等处 理; 利用归一化差值植被指数 (NDVI), 分期提取了红碱淖水域面积, 分析了湖水水质及红碱淖周围植被变化. 研究表明: $40 \mathrm{a}$ 间红碱淖水域面积呈阶段性萎缩趋势, $1990 \mathrm{~s}$ 后萎缩速率加剧, 水域面积总体缩小 $45.7 \%$; 湖区周边 NDVI 波动性增加 显示了水退草进的变化趋势; 湖面 NDVI 值的骤增, 暗示叶绿素 a 或悬浮物浓度增加, 间接表明湖区水质变差. 根据 $40 \mathrm{a}$ 来水域面积变化, 红碱淖的演变进程可依据湖泊面积动态度划分为稳定期 (1973-1994 年) 和萎缩期 (1994-2013 年) 两 个阶段,气候暖干化是影响稳定期 (1973-1994 年) 湖泊变化的主要因素,在萎缩期( 1994-2013 年)气候暖干化叠加人 类活动是湖泊水量减少和水质变差的诱因, 高强度的人为干扰如人工筑坝、灌溉耗水和煤炭开采是红碱淖水域面积锐减 的主要原因.
\end{abstract}

关键词: 红碱淖; 湖泊变化; $N D V I$;驱动力; 遥感监测 $; \mathrm{MSS} / \mathrm{TM} / \mathrm{ETM}^{+} / \mathrm{OLI}$

\section{Water quality variation of Lake Hongjiannao and its driving force analysis from 1973 to 2013}

\section{ZHAO Ning, MA Chao ${ }^{* *}$ \& YANG Yali}

( Key Laboratory of Mine Spatial Information Technologies of SBSM, Henan Polytechnic University, Jiaozuo 454000, P.R.China)

Abstract: With radiometric calibration, atmospheric correction, radiation normalization and band calculation on eight multispectral images from Landsat MSS, TM, ETM ${ }^{+}$and OLI from 1973 to 2013, the area and water quality (derived from NDVI) of Lake Hongjiannao and the vegetation coverage around the lake were acquired. The study showed that the area of the lake presented a stage of shrinking trend over the past four decades. Especially, after the 1990s the rate of decline was intensified, and it totally shrank by $45.7 \%$. Change of the $N D V I$ values in the buffer zone that the vegetation covered around the lake were generally improved with the fluctuations. At the same time, the $N D V I$ of water surface of the lake showed a statistically significant increasing trend, which suggested that chlorophyll-a or suspended substance was increasing and caused a degraded water quality. According to changes in lake water area, the evolution process of the lake can be divided into a stable stage (1973-1994) and a shrinking stage (1994-2013). Climate warming and drying had significant influence on change of the lake area during the stable stage. Climate change and human activities were the causes of the lake water area decrease and water quality variation. Intensive human activities, such as building reservoir, irrigation and coal mine exploitation were the dominant drivers for lake changes.

Keywords: Lake Hongjiannao; lake changes; NDVI; driving forces; remote sensing monitoring; MSS/TM/ETM ${ }^{+} / \mathrm{OLI}$

湖泊水资源变化记录了气候变化和人类活动对区域水文过程的影响, 及时、准确地获取湖泊的水资源 变化信息, 对认识区域乃至全球环境演变具有重要的参考意义 ${ }^{[1]}$. 红碱淖是我国最大的沙漠淡水湖, 全世界 最大的遗鸥繁殖与栖息地 ${ }^{[2]}$. 红碱淖湿地也被列为国家重要湿地自然保护区. 近年来,随着气候变化与人为 因素的干扰, 红碱淖面积逐年缩小、水质变差, 对周边居民生活和湿地生态环境造成了严重的影响. 因此, 开

* 国家自然科学基金委员会与神华集团有限责任公司项目 (培育项目 U1261106, 重点项目 U1261206) 资助. 2015 09-28 收稿;2016-01-01 收修改稿. 赵宁(1988 ) ,女,硕士研究生;E-mail: bzn612@ 163.com.

** 通信作者;E-mail: d_insar@ 126.com. 
展红碱淖水域时空变化特征的研究, 对减缓湿地的沙漠化进程、保护流域水生态安全及协调流域水资源开 发利用,兼具理论意义及应用价值.

相对于传统的监测技术, 光学传感器以其高时间分辨率、低成本的强大优势, 被广泛用于湖泊水域动态 变化监测以及变化分析 ${ }^{[3]}$. 国内外学者在监测手段、提取方法、植被覆盖变化及水质指数反演等方面取得了 一些成果. 如李辉霞等采用 SPOT/VGT 逐旬归一化植被指数 (NDVI) 数据分析近 $10 \mathrm{a}$ 三江源地区植被变化 趋势, 探讨植被生长与气候变化的响应机制, 定量评定气候要素与人类活动对 $N D V I$ 变化的贡献 ${ }^{[4]}$; Doña 等 结合高空间分辨率的 Landsat 影像和高时间分辨率的 MODIS 影像来监测 Albufera de Valencia 湖泊的水质参 数, 如叶绿素 $\mathrm{a}$ 与透明度, 并建立 GP 模型来分析湖泊水质的时空变化规律 ${ }^{[5]}$; 李均力等利用 Landsat 长时间 序列遥感数据, 制作了 4 期青藏高原湖泊分布图及湖泊变化图, 分析 30 多年来内陆封闭流域内湖泊变化的 时空特征 $^{[6]}$; 朱长明等通过 Landsat 影像监测近 $40 \mathrm{a}$ 博斯腾湖的面积、水位和库容量等水文信息, 分析了时 间动态变化过程与演变特征 ${ }^{[1]}$; Han 等对 11 期 Landsat 影像进行 SVM ( Support Vector Machines) 法影像分 类,分析 1973-2013 年鄱阳湖湿地土地利用的时空变化特征及土地类型转移情况 ${ }^{[7]}$. 但以往的研究大多数 仅针对面积, 目标单一, 缺乏对整个流域的系统性研究及综合分析, 不利于全局的把握及内外因的分析. 目 前, Landsat 系列卫星已交替运行 $40 \mathrm{a}$, 随着 2013 年 LDCM (Landsat Data Continuity Mission) 的发射成功, Landsat 系列卫星将持续为对地观测提供优良的数据集 ${ }^{[8]}$. 此数据集对地观测时间最长, 更适用于长时间序 列的变化分析; 其空间分辨率高, 从而在相同观测区域上, 获得更多的信息量, 更适用于中小尺度的对地 监测.

基于此,本文选取了 Landsat MSS/TM/ETM $/$ OLI 影像数据, 提取 1973-2013 年间 8 期研究区 NDVI 影 像, 分析湖泊面积、水质及湖泊周围植被的变化规律; 采用插值法获取该区的气象数据, 从气候变化和人类 活动两方面阐述湖泊变化的原因. 以期更深人地认识沙漠湖泊演化规律及气候变化和人为干扰对其的影 响, 为沙漠湖泊资源的合理开发、利用和保护提供理论依据.

\section{1 研究区及数据来源}

\section{1 研究区}

红碱淖 ( $38^{\circ} 13^{\prime} \sim 39^{\circ} 27^{\prime} \mathrm{N}, 109^{\circ} 42^{\prime} \sim 110^{\circ} 54^{\prime} \mathrm{E}$ ) 位于陕西省神木县与内蒙古鄂尔多斯市陕蒙交界处, 处 于黄土高原与内蒙古高原过渡地带、毛乌素沙漠与鄂尔多斯盆地交汇处, 海拔 $1200 \mathrm{~m}$. 有扎莎克河、壕赖河、 松道河、东葫芦素河、七卜素河、前尔林兔河、马连河 7 条季节性河流注人, 流域面积约 $1500 \mathrm{~km}^{2}$ (图 1).

研究区属黄河流域内陆闭流区范围, 为温带半干旱大陆性季风气候, 干燥多风, 四季界限分明. 降雨偏 少且年内分配不均,多以暴雨形式集中在 7-9 月, 年均降雨量在 $400 \mathrm{~mm}$ 左右. 湖区周边大部分为固定沙丘 和沙蚀丘陵, 植被种群为典型的沙生植被, 如白刺 (Nitraria tangutorum)、油蒿 (Artemisia ordosica)、沙柳 (Salix cheilophila ) 等, 植被覆盖度为 $30 \% \sim 50 \%{ }^{[2]}$, 而沙丘中间低处生长有零星的树木. 该流域有遗鸥 ( Larus relictus)、黑鹳 (Ciconia nigra)、金雕( Aquila chrysaetos) 等 30 多种野生珍禽繁殖栖息,水生生物种类繁多,具有很 高的生态地位.

\section{2 数据来源}

卫星影像采用 Landsat MSS、TM、 $\mathrm{ETM}^{+}$和 OLI 数据. 通过美国地质调查局网站 (http://www.usgs. gov/) 免费 获取 8 期研究区数据, 数据影像为 L1T 级, 质量良好, 含 云量较低,已经过几何校正, 不同数据间达到高精度配 准. 数据集中为一年中的 $8-11$ 月, 以确保每期具有相 近的气候条件和水文条件. Landsat 影像具体信息见 表 1 .

气象数据源于中国气象科学数据共享服务网 (http://cdc.nmic.cn/home.do). 由于红碱淖区域并未设 置气象站点, 且气象数据集所覆盖站点分布较为稀疏,
表 1 研究采用的 Landsat 影像数据集

Tab.1 Landsat images used in the study

\begin{tabular}{cccc}
\hline 日期 & 轨道号 & 平台与传感器 & 分辨率/m \\
\hline $1973-11-25$ & P137R33 & Landsat1 MSS & 60 \\
$1978-08-19$ & P137R33 & Landsat3 MSS & 60 \\
$1989-09-11$ & P127R33 & Landsat5 TM & 30 \\
$1994-08-24$ & P127R33 & Landsat5 TM & 30 \\
$1999-10-17$ & P127R33 & Landsat7 ETM & 30 \\
$2002-11-02$ & P127R33 & Landsat5 TM & 30 \\
$2007-08-12$ & P127R33 & Landsat5 TM & 30 \\
$2013-09-13$ & P127R33 & Landsat8 OLI & 30 \\
\hline
\end{tabular}




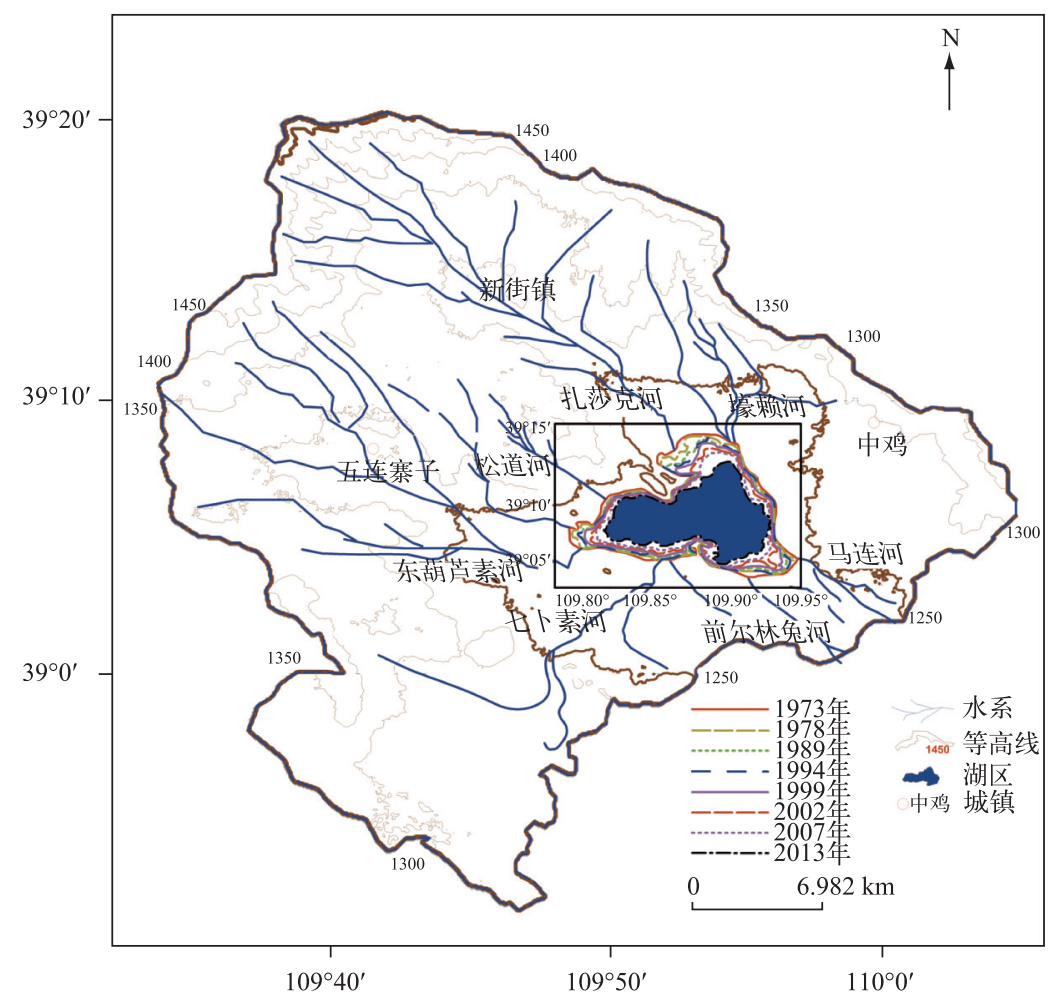

图 1 研究区地理位置

Fig. 1 Location of the study region

故选取了 1973-2013 年陕西、内蒙古境内共 69 个站点 (图 2) 的气象数据, 在 ArcGIS 中采用反距离空间加 权插值法获取研究区气象数据. 该气象数据空间分辨率与观测卫星相同.

\section{2 数据处理}

\section{1 辐射定标和大气校正}

影像原始数据值为 DN 值, 对图像做辐射定标、大气校正等预处理, 将 DN 值转化为地物的真实反射信 息. 首先, 对 6 幅非 MSS 图像进行重采样, 使其空间分辨率为 $60 \mathrm{~m}$, 从而与 MSS 影像相配准, 采样方法为最 邻近像元法. 其次, 将原始 DN 值转换为传感器人瞳处辐亮度值, 计算公式为:

$$
L_{\lambda}=\operatorname{Gain} \cdot D N_{\lambda}+\text { Bias }
$$

式中, $L_{\lambda}$ 为传感器接收到的辐亮度值 $\left(\mathrm{W} /\left(\mathrm{cm}^{2} \cdot \mu \mathrm{m} \cdot \mathrm{sr}\right)\right) ; D N_{\lambda}$ 为图像灰度值; Gain 和 Bias 分别为图像的 增益与偏置, 可从头文件中读取.

假设地面是朗伯面反射且天空辐照度各向同性, 将辐亮度 $L$ 转化为表观反射率 $\rho$, 表观反射率有利于不 同传感器的分析比较.

$$
\rho_{\lambda}=\frac{\pi \cdot L_{\lambda} \cdot d^{2}}{E S U N_{\lambda} \cdot \cos \left(\theta_{\mathrm{s}}\right)}
$$

式中, $\rho_{\lambda}$ 为表观反射率; $d$ 为天文单位的日地距离; $E S U N_{\lambda}$ 为大气层外相应波长的太阳光谱辐射照度,两者 均可查得 ${ }^{[9]} ; \theta_{s}$ 为以度为单位的太阳天顶角, $\theta_{s}=90^{\circ}-$ 太阳高度角, 太阳高度角可通过头文件查得.

采用 FLAASH 算法进行大气校正. ENVI 提供的 FLAASH 模块是嵌人 MORTRAN4+辐射传输代码来校 正影像的,计算出的反射率精度高. FLAASH 模型最大可能利用图像本身信息, 对部分输人参数 (如能见度 初始值、大气模式等) 的敏感性并不体现出强依赖, 且其邻近效应处理环节大大提高了辐射校正的整体水 


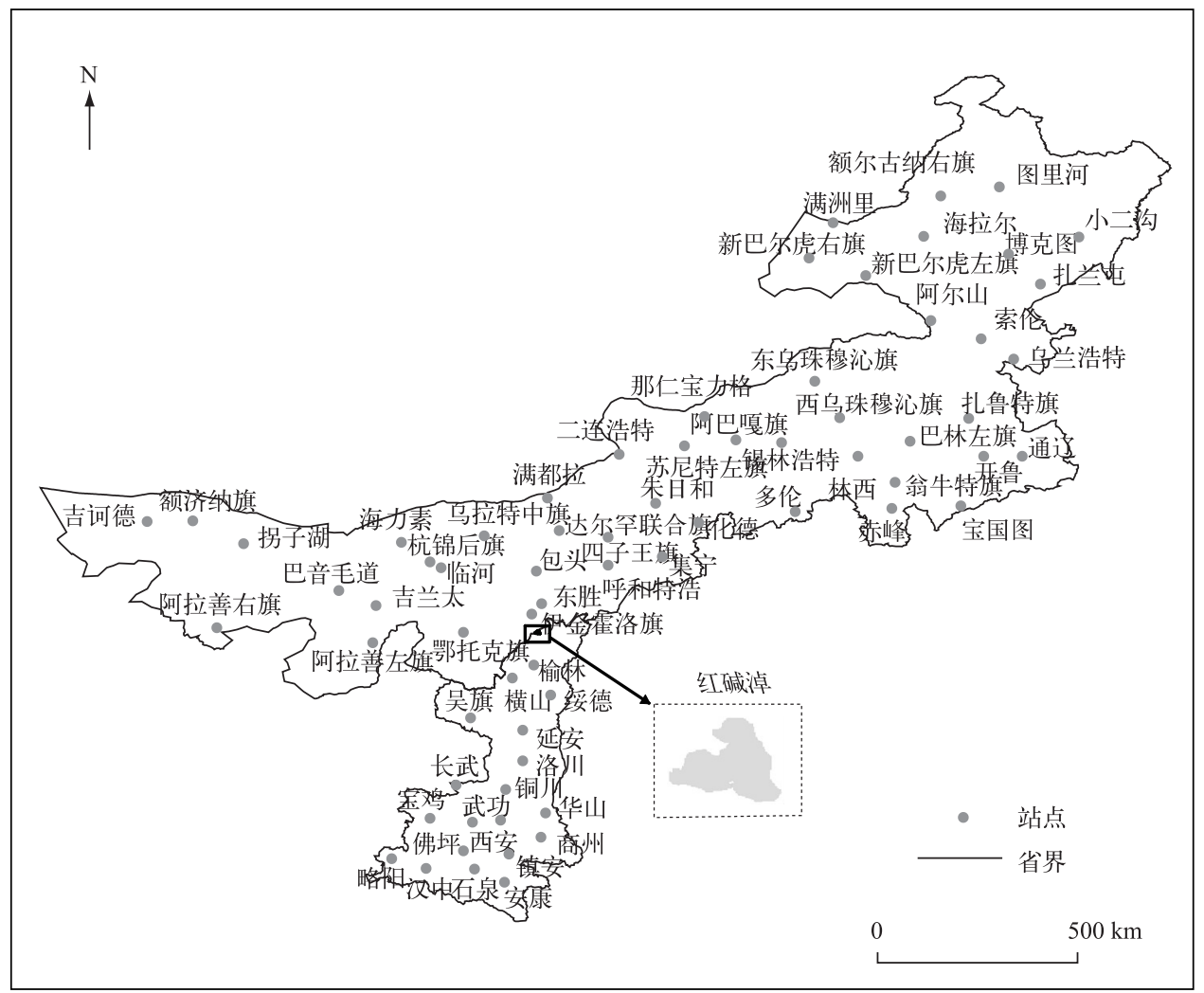

图 2 内蒙古和陕西省 69 个气象站点分布

Fig.2 Distribution of 69 weather stations in Inner Mongolia and Shanxi Province

平, 因而在数据处理中尤其是针对历史数据, FLAASH 算法更加适用 ${ }^{[6,10]}$.

FLAASH 模块主要参数选择: 区域平均海拔为 $1.2 \mathrm{~km}$; 气溶胶模型选为乡村, 并使用 K-T 气溶胶反演方 法, 即暗像元法. 因为对于暗像元, 近红外通道反射率与红蓝通道反射率具有很好的线性关系, 同时气溶胶 在短波红外波段的影响与可见光波段相比可以被忽略 ${ }^{[11]}$; 由于缺少相应波段不执行水汽反演.

\section{$2.2 N D V I$ 的获取与数据同化}

$N D V I$ 是近红外波段与可见光波段数值之差和这两个波段数值之和的比值, 即:

$$
N D V I=\frac{\rho_{\mathrm{NIR}}-\rho_{\mathrm{R}}}{\rho_{\mathrm{NIR}}+\rho_{\mathrm{R}}}
$$

相较于其他植被指数, 归一化植被指数应用最为广泛. $N D V I$ 可以用于监测植被生长的季节和年际变 化, 并减少由卫星观测角、太阳光照差异、地形、云阴影和部分大气衰减等引起的噪声, 增强对植被响应的能 力. NDVI 用非线性拉伸的方式增强了近红外与红色通道反射率的对比度, 其结果是对于低值部分有所拉 伸, 而高值部分受到压缩, 使得 $N D V I$ 对低覆盖植被区的灵敏度提高, 所以 $N D V I$ 特别适合于本文的荒漠化草 原植被研究.

多时相遥感数据由于受到不同的大气条件、光照条件、土壤湿度状况、物候周期特性等环境参数的影 响,使同一地区所成的影像具有较大的辐射差异. 而传感器不同将导致波段位置和宽度不同,其波谱响应函 数也不同, 从而使传感器所接收的红光和近红外波段信号存在差异. 为此, 在利用多源遥感影像进行变化检 测之前, 需要进行辐射同化, 以控制和减少非地物变化所造成的辐射差异. 辐射同化即辐射归一化, 是基于 参考影像来校正待校正影像, 使不同时相影像上的相对稳定的同名地物具有相同的辐射特性. 在研究中, 由 
于 1999 年获取的 $\mathrm{ETM}^{+}$影像无云层覆盖, 影像质量良好, 所以选用该年度的 NDVI 图像作为参考影像, 对其 他年份的 NDVI 图像进行归一化处理.

采用基于线性回归分析法的伪不变特征法进行辐射归一化处理. 伪不变特征法根据变量之间的相互关 系来模拟回归方程, 具有严密的数学逻辑, 从而能准确地反映出变量之间的关系. 两时相影像不变像元的辐 射关系是线性的, 而且在影像范围内大气分布均匀. 因此可用回归方程来实现影像的 NDVI 值归一化处理:

$$
y=a \cdot x+b
$$

式中, $x$ 为待校正影像的 NDVI 值; $y$ 为参考影像的 NDVI 值; $a 、 b$ 为待定参数, 可通过选取伪不变特征点 (PIF) 来计算待定参数. 虽然有些变化是不可避免的, 但是 PIF 的光谱特征应该随时间变化很小, 如未受扰 动的沙地、裸地、深水体等地物. 研究选用沙地和深水体两类地物作为 PIF, 分别求得 1999 年参考影像与其 余 7 幅影像的归一化方程及对应相关系数的平方 $\left(R^{2}\right) .7$ 个 $R^{2}$ 值均大于或等于 0.99 (图 3 ), 即参考影像与 待校正影像的对应 PIF 有很强的相关性,因此以所求方程进行转换的可靠性极高.
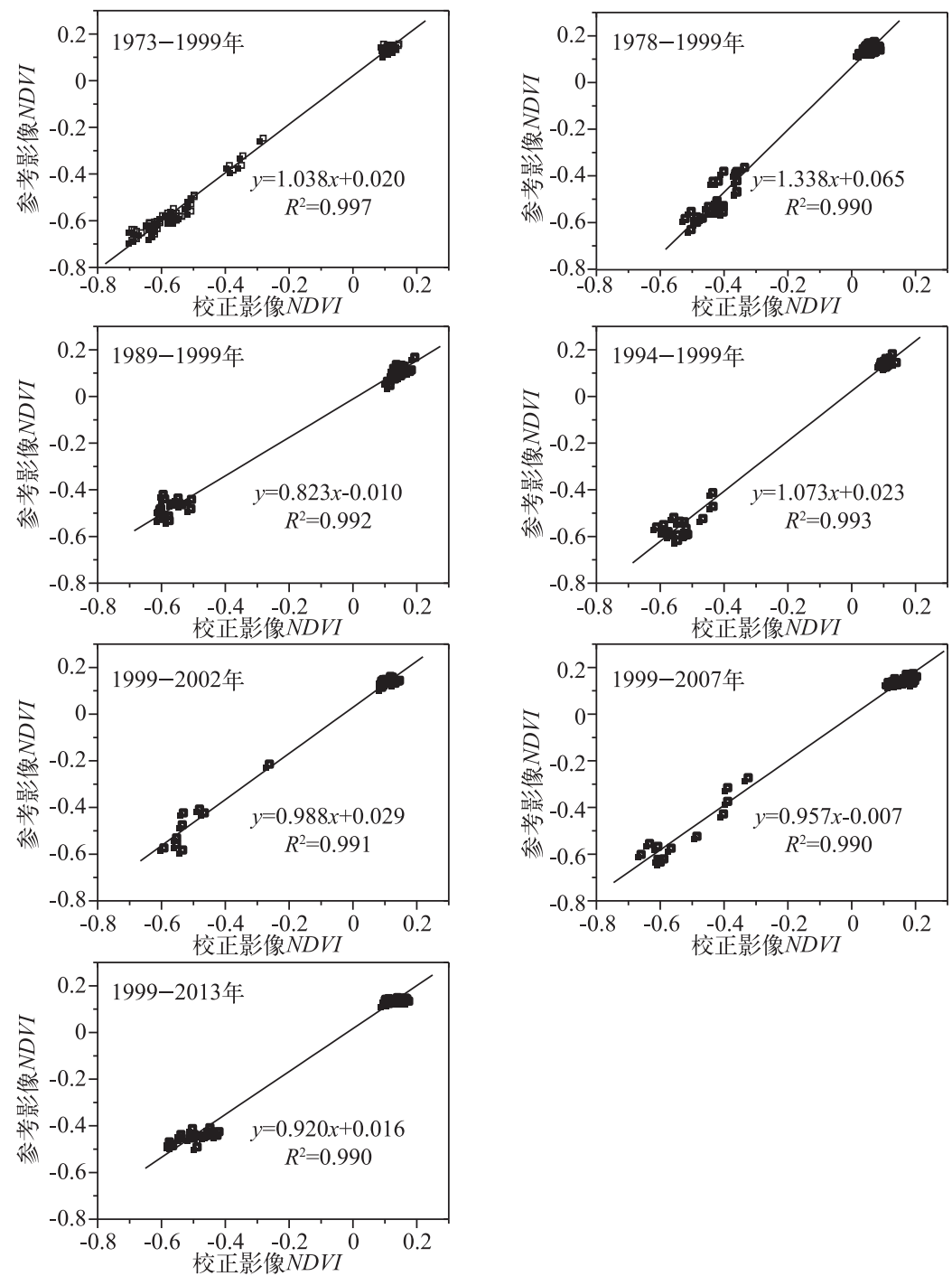

图 3 求解的回归方程及 $R^{2}$

Fig.3 Regression equation and $R^{2}$ 


\section{3 湖泊面积矢量提取}

由于水体的 $N D V I$ 值极低,所以利用 $N D V I$ 图像能清晰地辨别水陆边界, 通过人机交互方式, 提取 8 期红 碱淖湖泊水域的矢量信息, 建立 8 期红碱淖湖泊矢量图层. 图 4 显示了这 8 期影像所对应的 8 条红碱淖水陆 边界线.

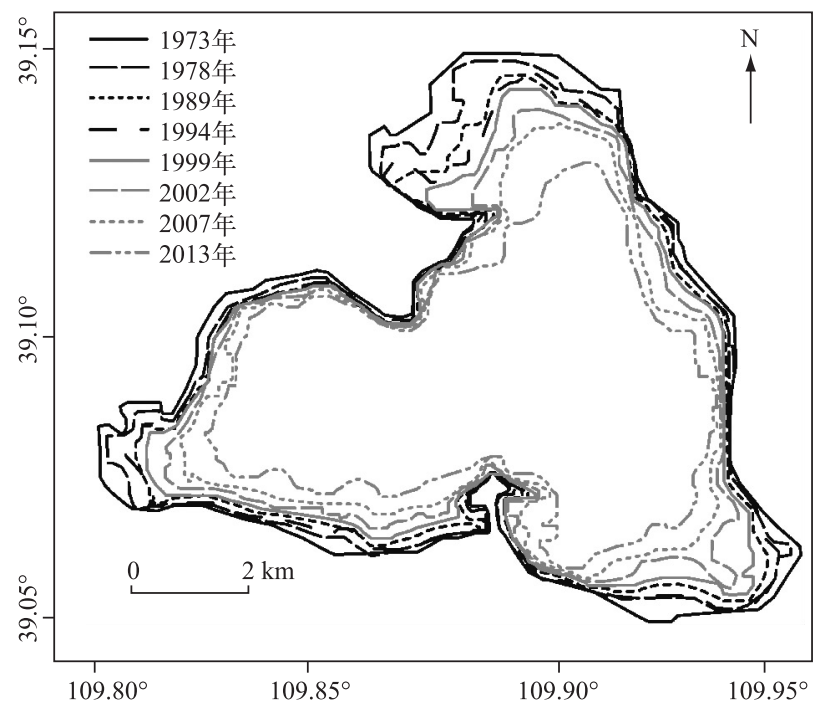

图 4 1973-2013 年多时相影像的红碱淖水陆边界线

Fig.4 Boundary lines of Lake Hongjiannao extracted from multi-temporal images from 1973 to 2013

\section{4 湖泊面积动态度}

利用湖泊面积动态度分析湖泊变化特征, 可以真实地反映不同时期湖泊面积变化的剧烈程度. 湖泊面 积动态度是指某研究区一定时间范围内湖泊面积的变化, 其表达式为 ${ }^{[12]}$ :

$$
L C=\frac{U_{\mathrm{b}}-U_{\mathrm{a}}}{T U_{\mathrm{a}}} \times 100 \%
$$

式中, $L C$ 为研究时段内湖泊面积动态度, $U_{\mathrm{a}}$ 和 $U_{\mathrm{b}}$ 分别为研究初期和研究末期的湖泊面积, $T$ 为研究时长.

\section{3 结果与分析}

\section{1 红碱淖面积变化}

1973-1994 年期间红碱淖面积持续缩小,从 1973 年的 $58.33 \mathrm{~km}^{2}$ 减少到 1994 年的 $53.20 \mathrm{~km}^{2}, 21$ 年间 水域面积共减少 $5.13 \mathrm{~km}^{2}$, 缩小了 $8.79 \%$; 1994-2013 年该湖区面积变化率增大, 2013 年湖区面积仅为 31.67 $\mathrm{km}^{2}$, 比 1994 年缩小了 $40.47 \%$ (表 2). 可见,研究时段 (1973-2013 年) 内湖泊面积整体呈阶段性萎缩趋势, 1973-1994 年间为相对稳定期, 而 1990s 中期开始进人 萎缩期; $40 \mathrm{a}$ 间水域面积总体减小 $26.66 \mathrm{~km}^{2}$, 共缩小 $45.7 \%$ (图 5a).

研究选用数据不是等时间间隔数据, 所得变化量不 能反映面积变化的剧烈程度,需根据湖泊面积动态做进 一步定量分析. 稳定期湖泊面积年变化率小于 $-0.59 \%$, 萎缩期年变化率大于 $-2.03 \%, 2007-2013$ 年年变化率 表 2 红碱淖面积变化动态度

Tab.2 Dynamic degree of Lake Hongjiannao area

\begin{tabular}{cccc}
\hline 年份 & 面积 $/ \mathrm{km}^{2}$ & $\left(U_{\mathrm{b}}-U_{\mathrm{a}}\right) / \mathrm{km}^{2}$ & $L C / \%$ \\
\hline 1973 & 58.33 & -0.112 & -0.19 \\
1978 & 57.77 & -0.342 & -0.59 \\
1989 & 54.00 & -0.160 & -0.30 \\
1994 & 53.20 & -1.080 & -2.03 \\
1999 & 47.80 & -1.420 & -2.97 \\
2002 & 43.54 & -0.940 & -2.16 \\
2007 & 38.84 & -1.195 & -3.08 \\
2013 & 31.67 & & \\
\hline
\end{tabular}
达到 $-3.08 \%$ (表 2). 可见,萎缩期相对稳定期变化十分 
剧烈, 是湖域面积减小的主要时期.

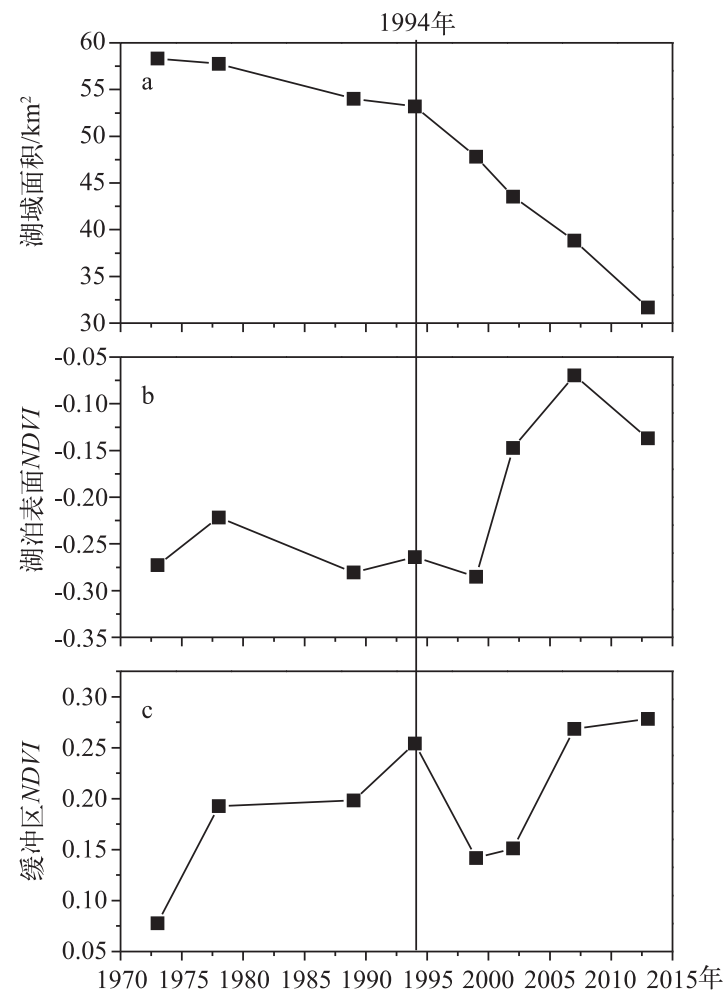

图 5 1973-2013 年红碱淖面积及 NDVI 值的变化

Fig.5 Changes of Lake Hongjiannao area and NDVI values from 1973 to 2013

红碱淖湖区呈三角形状, 在 8 期 $N D V I$ 图像上设置了 $1^{\#}$ 和 $2^{\#}$ 两条剖面线, 获得 $N D V I$ 时间序列剖面图 (图 6), NDVI 值小于 0 的部分为湖水区, 大于 0 的为陆地. 由于扎莎克河、壕赖河、前尔林兔河、东葫芦素河 的注水量从减少到断流, 时间序列 NDVI 图像清晰见证了红碱淖形状和大小的显著变化, 如 1973 年在湖区 周围可以明显看到一些小规模的湖沼, 随年份的增长, 逐渐干涸成为沙地; 1989 年右下角的湖面逐渐与湖体 分离, 形成牛轭湖, 最后形成新月形的沙湾; 下方的湖心岛, 由于水位下降, 2002 年成为半岛, 最后演化成稳 定的湖岸等.

\section{2 红碱淖周围植被变化}

植被作为陆地生态系统的主体, 在很大程度上代表了一个地区环境的总体状况. 本文设置的缓冲区是 从红碱淖最外边界向外扩展 $19 \mathrm{~km}$, 使 7 条季节性补给水源均被包含在缓冲区内. 由图 5c 可见, 缓冲区 $N D V I$ 均值呈波动性增长模式, 在 1999 年出现的波谷是湖水退却之后植被的形成期, 其后 1999-2013 年保 持稳定的增长趋势, 水退草进, 植被占据了原来的湖区.

\section{3 红碱淖水质变化}

对于环境简单的沙漠内陆湖泊, 影响其水质变化的主要因素有二: 悬浮物浓度和浮游植物生物量, 两者 主要由沙漠区严重的水土流失引起. 悬浮物浓度多少直接影响水体透明度、浑浊度和水色等光学性质, 而浮 游植物生物量常用叶绿素 a 估测. 叶绿素 a 在 440 和 $675 \mathrm{~nm}$ 附近形成两个吸收峰, 在 $550 \mathrm{~nm}$ 附近达到吸收 最小值, 随其浓度的升高, 将在 700 800 nm 波段出现突出的反射峰 ${ }^{[13-15]}$. 对悬浮物的研究表明, 500 600 $\mathrm{nm}$ 波段适合用来监测悬浮物, 700 900 nm 波段悬浮物浓度变化敏感, 是遥感估算的最佳波段 ${ }^{[14,16-17]}$.

利用 NDVI 值分析水质变化是经验法的一种,基于近红和红波段的最佳波段组合,两波段与叶绿素 $\mathrm{a} 、$ 悬 浮物均较相关. 当叶绿素 a 浓度介于 $10 \sim 100 \mu \mathrm{g} / \mathrm{L}$ 之间时, 与 $N D V I$ 值表现出较好的线性正相关关系 ${ }^{[18-19]}$. 


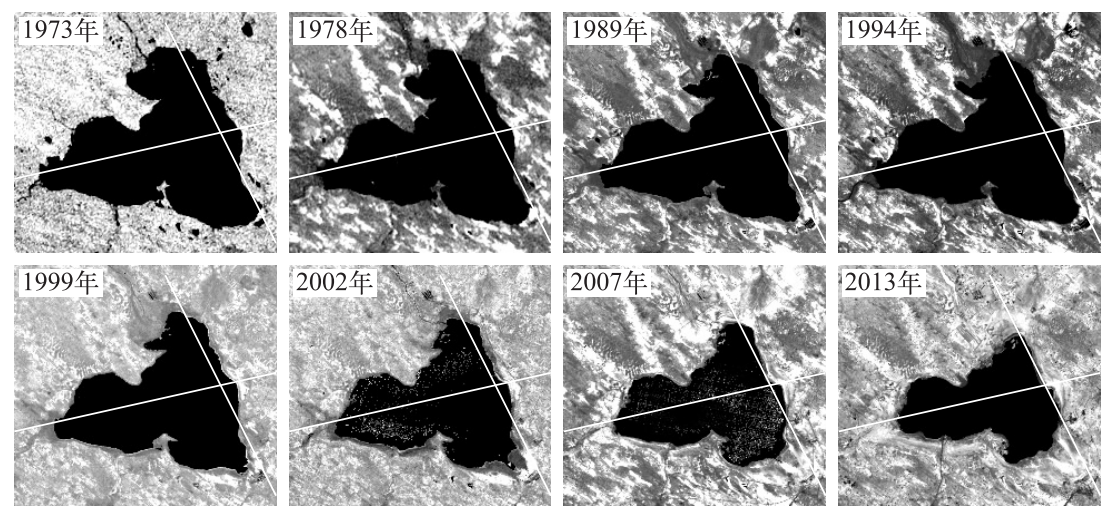

图 6 1973-2013 年红碱淖时间序列 NDVI 图像

Fig.6 Time series NDVI images of Lake Hongjiannao from 1973 to 2013

对于藻类浓度较低的湖泊, 有实验表明悬浮物与 $R_{N D V I}\left(N D V I\right.$ 值) 表现出很好的线性关系 ${ }^{[20]}$. 相对一般内陆 湖泊, 红碱淖水污染较轻, 各水质参数值也不高, 可以用 $N D V I$ 值分析两者的变化, 但因 Landsat 系列卫星波 段设置较宽,很难进一步分离两者间的相互影响,仅能定性说明两者所表示的水质变化情况 ${ }^{[20-22]}$. 湖面 $N D V I$ 值总体呈增长趋势, 且除 2007 年为暴发式增长外, 其余年份均为叠加式缓慢增长, 而且水体中 $N D V I$ 剧增与湖面面积骤降几乎是同时发生的. 水域面积的剧烈变化、水深减小都可能导致水中悬浮物增加、透明 度减弱、近岸浅水区水生植物增加, 导致红碱淖水质变差, 但 $N D V I$ 值大多数时间小于 0 , 并未出现蓝藻水华 现象 (图 7). 1973-1999 年 $N D V I$ 增加 $0.47 \times 10^{-3}, 1999-2013$ 年 $N D V I$ 增加 0.011 (图 5b).

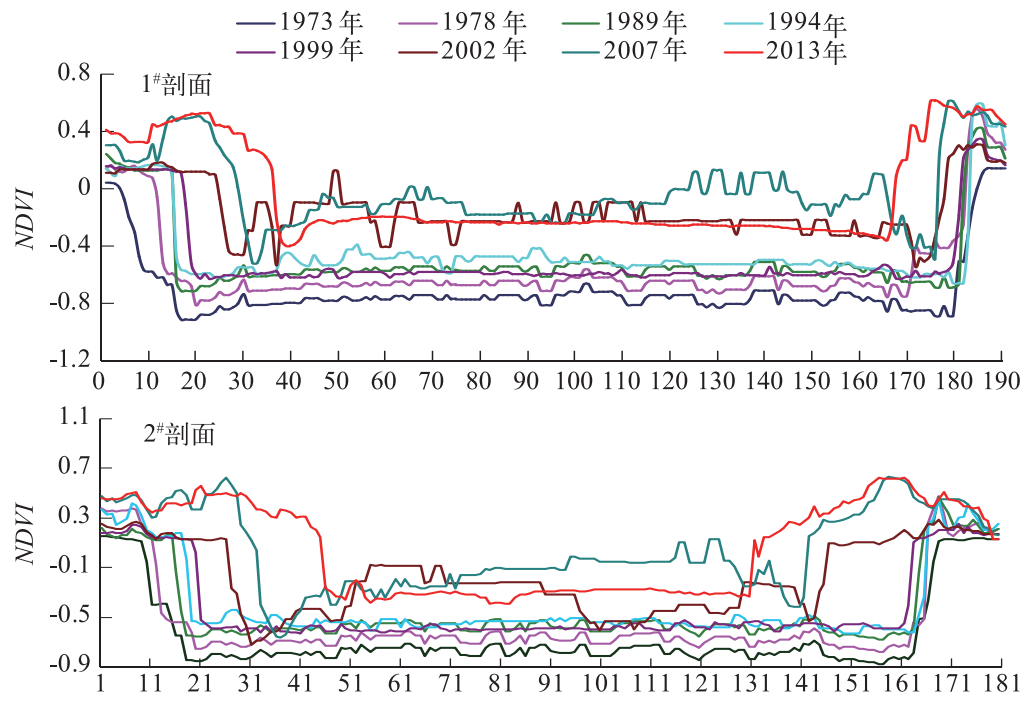

图 $71973-2013$ 年 $1^{\#}$ 与 $2^{\#}$ 剖面线的 $N D V I$ 变化

Fig.7 NDVI values of No.1 and No.2 profiles from 1973 to 2013

\section{4 驱动力分析}

红碱淖水域面积和水质变化的原因一方面是自然因素,如气候的变化;另一方面是人类活动的影响.

\section{1 气候暖干化}

受全球气候变暖的影响,红碱淖研究区气候呈暖干化变化趋势. 
由 69 个气象站资料获得的湖区周围 $41 \mathrm{a}$ 温度数据 (图 $8 \mathrm{a}$ ) 可知, 红碱淖地区年均温度呈阶段性变化, 即 1973-1984 年年均温度呈下降趋势, 1984-1998 年年均温度呈上升趋势, 1998- 2013 年年均温度相对平 稳. 但总体呈上升趋势, 增温速率为 $0.033^{\circ} \mathrm{C} / \mathrm{a}$.

由 69 个气象站资料获得的湖区周围 $41 \mathrm{a}$ 降水量数据 (图 8b) 可知, 红碱淖年均降水在波动中下降, 年 均降水量下降速率为 $0.013 \mathrm{~mm} / \mathrm{a} .1973-2013$ 年的 $41 \mathrm{a}$ 年均降水量的平均值为 $390 \mathrm{~mm} / \mathrm{a}$, 湖区降水围绕 $390 \mathrm{~mm}$ 等降水量线上下波动,除 1978 和 2003 年两个骤然高值外, 出现 1981-1984 年、2007-2011 年两期 降水连续走低的阶段.

综上所述, 红碱淖受温度升高与降水减少共同作用,红碱淖水域面积变化与温度的长期变化趋势相吻 合, 即随温度的升高, 蒸散量加大, 从而导致湖泊面积减小; 红碱淖地处年均降水量极低的干旱区, 面积与降 水的变化趋势总体相一致, 但相关性较低, 不考虑地表径流的补给作用, 即使在连续干旱的 $1981-1984$ 年, 水域面积并没有出现显著性减少. 缓冲区陆表 $N D V I$ 值与降水的变化波动特征存在较显著的耦合关系. 而湖 区 $N D V I$ 值变化只在 1973-1999 年与降水变化波动相一致,与同期温度变化相关性较差. 可见, 气候变化是 影响红碱淖流域生态系统变化的原因之一.
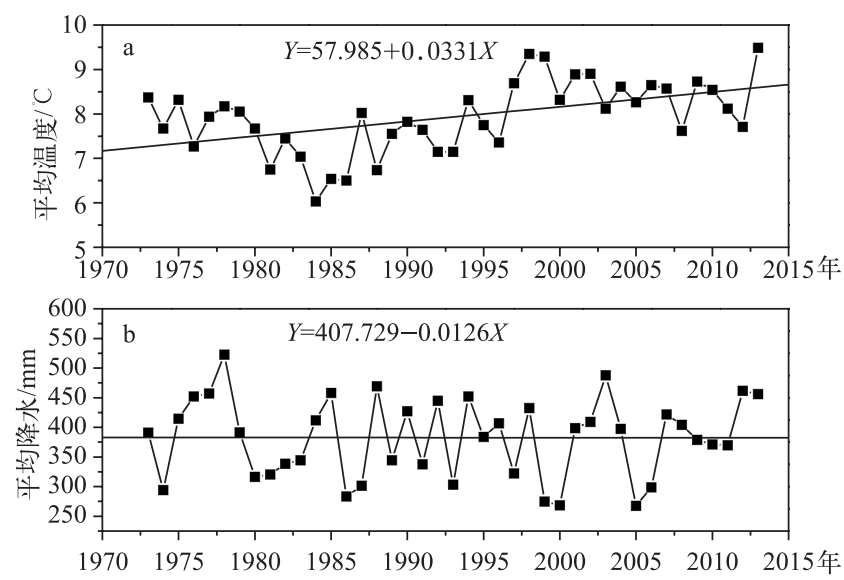

图 $81973-2013$ 年年均气候因素变化

Fig.8 Changes of climatic factors from 1973 to 2013

\section{2 人类活动的影响}

1) 人工水库和大坝阻断地表水补给. 7 条季节性河流是红碱淖的主要地表水补给源, 近年来, 人为阻断 已严重影响了河流的补给作用. 1997-2004 年期间, 内蒙古在扎莎克河、壕赖河这两条主要河流上修筑了多 个小型水库以及人工湖 ${ }^{[1,23]} .2005$ 年, 建成扎莎克水库大坝, 阻断了红碱淖最大的注水河流扎莎克河 ${ }^{[24]}$. 2009 年, 在东葫芦素河建造地下水库, 使该河流遭到断截 ${ }^{[25]}$. 注水河流被拦截, 极大地减少了河水的注人 量, 导致 1994 年之后湖泊面积萎缩幅度增强, 2007-2013 年湖泊面积动态度高达-3.08\%,变化越来越剧烈.

2) 农业灌溉和生态林建设. 1990s 以后, 区内农业灌溉面积逐年增加. 以尔林兔镇为例, 1995 年水浇地 面积为 $840 \mathrm{hm}^{2}, 2003$ 年则为 $1720 \mathrm{hm}^{2[26]}$. 大规模地抽取地下水进行灌溉, 使得地下水位下降, 导致地下水 补给量减少. 同时生态林建设势必会影响到红碱淖地区的植被覆盖, 2006 年开始, 红碱淖实施了环湖绿化生 态环境改善工程,造林约 $1334 \times 10^{4} \mathrm{~m}^{2}$, 湖区周边的绿化面积从 $20 \%$ 提升到 $45 \%{ }^{[27]}$. 研究显示, 2007-2013 年 NDVI 值并未随温度升高和降水下降而减少, 这正与该工程之后所呈现的生态效应相对应. 但生态建设在 干旱地区存在水量保证程度差的问题, 当地 $400 \mathrm{~mm}$ 左右的降水不能满足植被生长对水分的需求, 需要利用 浅层地下水.

3) 煤矿开采的潜在影响. 红碱淖周边煤炭资源极其丰富, 大规模的煤炭开采造成地表塌陷、地下含水层 结构破坏, 导致局部地下水流场发生变化, 土地沙漠化加剧和植被退化. 2009 年, 神木县前尔林兔河附近地 下水下降 $5.32 \mathrm{~m}, 20$ 多个泉眼干涸 ${ }^{[25]}$. 同时, 以煤化工为主的工业化工基地需集中供水,耗水量极大. 工业 
排放和当地开发的旅游业使湖水富营养化加剧, 矿物元素增加使叶绿素含量增高, 对水质产生影响.

\section{5 讨论}

研究表明, 红碱淖湿地面积从 1997 年后变化剧烈, 鱼类产量减少, 鸹鹚 (Phalacrocorax carbo) 等水鸟已 消失, 水生态退化 ${ }^{[23]}$. 本文同样发现 1990s 中期后面积变化剧烈, 并划分了面积变化的稳定期和萎缩期, 这 种划分与杨立涁等和唐克旺等对红碱淖面积变化的分析结果相似 ${ }^{[24,28]}$. 红碱淖流域蕴藏着复杂多样的植物 群落, 能有效地调节大气组分, 李登科等认为红碱淖湿地植被变化可分为 4 个阶段: $1982-1988$ 年植被覆盖 持续增加; 1989-1998 年相对稳定; 1999-2001 年维持较低;2002-2007 年快速升高,并分析认为近年湖区 植被变化受周围退耕还林等人为因素的影响明显, 本文的结论与其较为一致 ${ }^{[2]}$.

湿地是天然的过滤器, 可以降低流速, 净化水质, 有助于杂质和有毒物质的沉淀和排除. 湿地水分通过 蒸发变成水蒸气, 然后又以降雨的形式回归周围地区, 保持当地的湿度和降雨量, 调节局部小气候. 红碱淖 面积的萎缩使局部气候恶化, 降雨量减少, 将导致植被减少, 从而使湿地自净能力减弱, 加速湿地沙漠化 进程.

根据水量平衡原理, 红碱淖面积变化是其水量收支状况的反映, 水量收人主要包括降水补给、地表水补 给和地下水补给, 支出部分为湖区蒸散作用. 稳定期, 红碱淖流域收支基本稳定, 气候变化是水域变化的主 要原因; 萎缩期, 人类活动使地表水断流, 地下水过度开采, 成为影响红碱淖变化的主要原因, 即受气候因素 的影响相对减弱, 受人为因素的影响显著, 这与 Tao 等对蒙古高原内陆湖泊的研究结果一致 ${ }^{[29]}$.

\section{6 结论与建议}

$40 \mathrm{a}$ 间,红碱淖水域在面积和水质上都发生了沧海桑田的变化.

1) 红碱淖水域面积呈阶段性萎缩趋势, 在 1994 年前后划分为两个主要阶段: 1973-1994 年间湖泊面积 动态度小于 $-0.59 \%$, 受气温增高和降水减少的共同作用; $1994-2013$ 年湖泊面积动态度大于 $-2.03 \%$, 在区 域暖干化背景下, 受人工筑坝阻断地表补给、农林灌溉耗水减少地下补给、煤矿开采破坏含水层的共同作 用, 水域面积减少了 $26.66 \mathrm{~km}^{2}$, 水域面积总体缩小 $45.7 \%$.

2) 湖区 $N D V I$ 值呈上升趋势, 表明叶绿素 a 或悬浮物浓度增加, 水质变差; 同时缓冲区 $N D V I$ 值变化显示 近岸植被及湖区周边植被覆盖度呈波动性增加趋势. 气候变化和人工建库建坝导致 7 条季节性河流的主要 地表水补给能力下降、沙漠化使湖域水深变浅、工业排放和当地旅游业开发使湖水富营养化加剧, 使红碱淖 水质变差.

近年来, 人为干扰的强度有增无减, 其作用远超气候变化带来的自然演变, 为了避免沙漠中最大的淡水 湖一红碱淖成为 “第二个罗布泊”, 提出如下建议:

1) 在生产生活用水与生态用水出现严重对立的情况下, 提倡科学用水, 改变传统灌溉方式, 提高水的利 用率.

2) 严格按照环境影响评价标准,评估煤矿开采的经济效益与社会效益,减少耗水项目,控制旅游资源的 过渡开发, 维护区域生态平衡.

致谢: 感谢遥感专业 2012 级本科生王拿同学在数据预处理方面所做的工作.

\section{7 参考文献}

[ 1 ] Zhu Changming, Li Junli, Zhang Xin et al. Bosten water resource dynamic detection and feature analysis in recent 40 years by remote sensing. Journal of Natural Resources, 2015, 30(1) : 106-114(in Chinese with English abstract). [ 朱长明, 李 均力, 张新等. 近 $40 \mathrm{a}$ 来博斯腾湖水资源遥感动态监测与特征分析. 自然资源学报, 2015, 30(1) : 106-114.]

[ 2 ] Li Dengke, He Huijuan, Liu Anlin. Impact of human activities and climate change on vegetation around Hongiiannao Lake in northwestern China. Journal of Desert Research, 2010, 30(4): 831-836(in Chinese with English abstract). [李登科, 何慧娟, 刘安麟. 人类活动和气候变化对红碱淖植被覆盖变化的影响. 中国沙漠, 2010, 30(4) : 831-836. ]

[ 3 ] Liu Yang, You Hui, Cheng Xiao et al. Estimation of variation of Poyang Lake area based on long-term MODIS observations. Journal of Geo-Information Science, 2013, 15(3) : 469-475 (in Chinese with English abstract). [ 刘洋, 尤慧, 程晓 
等. 基于长时间序列 MODIS 数据的鄱阳湖湖面面积变化分析. 地球信息科学学报, 2013,15(3): 469-475. ]

[ 4 ] Li Huixia, Liu Guohua, Fu Bojie. Response of vegetation to climate change and human activity based on NDVI in the Three-River Headwaters region. Acta Ecologica Sinica, 2011, 31(19) : 5495-5504( in Chinese with English abstract). [李 辉霞, 刘国华, 傅伯杰. 基于 NDVI 的三江源地区植被生长对气候变化和人类活动的响应研究. 生态学报, 2011, 31(19): 5495-5504.]

[ 5 ] Doña C, Chang N, Caselles V et al. Integrated satellite data fusion and mining for monitoring lake water quality status of the Albufera de Valencia in Spain. Journal of Environmental Management, 2015, 151: 416-426.

[ 6 ] Li Junli, Sheng Yongwei, Luo Jiancheng et al. Remotely sensed mapping of inland lake area changes in the Tibetan Plateau. J Lake Sci, 2011, 23(3) : 311-320(in Chinese with English abstract). DOI: 10.18307/2011.0301.[李均力, 盛永 伟, 骆剑承等. 青藏高原内陆湖泊变化的遥感制图. 湖泊科学, 2011, 23(3): 311-320.]

[ 7 ] Han X, Chen X, Feng L. Four decades of winter wetland changes in Poyang Lake based on Landsat observations between 1973 and 2013.Remote Sensing of Environment, 2014, 156: 426-437.

[ 8 ] Zhang Wuyan, Ma Chao, Liu Qingchen. Radiation conversion equations of the Landsat series of sensors - A study case of MSS, TM and ETM+ images over the ORDOS region. Journal of Geomatics Science and Technology, 2014, 31(3) : 288293( in Chinese with English abstract). [张舞燕, 马超, 刘清臣. 美国陆地卫星三代光学传感器的辐射转换方程一 以鄂尔多斯地区 MSS/TM/ETM+影像为例. 测绘科学技术学报, 2014, 31(3):288-293.]

[ 9 ] Chander G, Markham BL, Helder DL. Summary of current radiometric calibration coefficients for Landsat MSS, TM, ETM+, and EO-1 ALI sensors. Remote Sensing of Environment, 2009, 113(5) : 893-903.

[10] Yang Xiaojun, Cheng Yusheng, Zhang Ye. Effect on atmospheric correction by inputting parameters of FLAASH model. Remote Sensing Information, 2008, (6) : 32-37 (in Chinese with English abstract). [ 杨校军, 陈雨时, 张华. FLAASH 模型输人参数对校正结果的影响. 遥感信息, 2008, (6): 32-37.]

[11] Wang Zhongting, Cheng Liangfu, Gong Hui et al. Modified DDV method of aerosol optical depth inversion over land surfaces from CBERS02B. Journal of Remote Sensing, 2009, (6) : 1047-1059( in Chinese with English abstract). [王中挺, 陈良富, 巩慧等. CBERS02B 卫星 CCD 传感器数据反演陆地气溶胶. 遥感学报, 2009, (6) : 1047-1059.]

[12] Xu Shi, Liu Zhiming, Wang Zongming et al. Dynamics of lake area changes and its driving force analysis in Jilin Province from 1986 to 2008. J Lake Sci, 2010, 22(6) : 901-909(in Chinese with English abstract). DOI: 10.18307/2010.0613. [许诗, 刘志明, 王宗明等. 1986-2008 年吉林省湖泊变化及驱动力分析. 湖泊科学, 2010, 22(6) : 901-909.]

[13] Shu Xiaozhou, Wang Junfa, Sheng Mingming et al. Remote sensing of water quality monitoring using airborne imaging spectrometer. J Infrared Millim Waves, 2000, 19(4): 273-276( in Chinese with English abstract). [ 疏小舟, 汪骏发, 沈 鸣明等. 航空成像光谱水质遥感研究. 红外与毫米波学报, 2000,19(4): 273-276.]

[14] Dekker AG, Peters SWM. The use of the Thematic Mapper for the analysis of eutrophic lakes: a case study in the Netherlands. International Journal of Remote Sensing, 1993, 14(5) : 799-821.

[15] Zhu Lingya. Remote sensing monitoring and assessment of water quality for lakes[Dissertation]. Beijing: Chinese Academy of Sciences( Institute of Remote Sensing Applications) ,2006(in Chinese with English abstract). [祝令亚. 湖泊水质遥感 监测与评价方法研究 [学位论文]. 北京: 中国科学院遥感应用研究所, 2006.]

[16] Gitelson A, Garbuzov G, Szilagyi F et al. Quantitative remote sensing methods for real-time monitoring of inland waters quality. International Journal of Remote Sensing, 1993, 14(7) : 1269-1295.

[17] Han L, Rundquist DC, Liu LL et al. The spectral responses of algal chlorophyll in water with varying levels of suspended sediment. International Journal of Remote Sensing, 1994, 15(18) : 3707-3718.

[18] Gu Liang, Zhang Yuchao, Qian Xin et al. Application of remote sensing index in retrieving Chlorophyll-a concentration of lakes. Environmental Protection Science, 2008, 34(2) : 53-56(in Chinese with English abstract). [顾亮, 张玉超, 钱新 等. 遥感指数在湖泊叶绿素 a 反演研究中的应用. 环境保护科学, 2008, 34(2): 53-56. ]

[19] Li Yunliang, Zhang Yunlin. Quantitative estimation of total suspended matter and Chlorophyll-a concentration of Taihu Lake in summer using TM data. Remote Sensing Information, 2008, (6) : 22-27 (in Chinese with English abstract). [ 李云 亮, 张运林. 基于 TM 影像的太湖夏季悬浮物和叶绿素 a 浓度反演. 遥感信息, 2008, (6): 22-27.]

[20] Zhou Weiqi. Monitoring of water quality parameters for inland waters by multi-spectral remote sensing data [Dissertation]. Beijing: Chinese Academy of Sciences (Institute of Remote Sensing Applications), 2004 (in Chinese with English abstract). [ 周伟奇. 内陆水体水质多光谱遥感监测方法和技术研究 [学位论文]. 北京: 中国科学院遥感应用研究 
所, 2004.]

[21] Zhou Yi, Zhou Weiqi, Wang Shixin et al. Application of remote sensing techniques to inland water quality monitoring. Advances in Water Science, 2004, 15(3) : 312-317 (in Chinese with English abstract). [ 周艺, 周伟奇, 王世新等. 遥感技 术在内陆水体水质监测中的应用. 水科学进展, 2004, 15(3): 312-317.]

[22] Pan Delu, Ma Ronghua. Several key problems of lake water quality remote sensing. J Lake Sci, 2008, 20( 2) : 139-144(in Chinese with English abstract). DOI: 10.18307/2008.0201. [潘德炉, 马荣华. 湖泊水质遥感的几个关键问题. 湖泊 科学, $2008, \mathbf{2 0}(2): 139-144$. ]

[23] Lou Guangyan, Wang Wenjun, Ge Lei et al. Water ecology status and protection measures for Hongjiannao basin. Journal of Hydroecology, 2012, 33(2) : 147-152( in Chinese with English abstract). [ 娄广艳, 王文君, 暮雷等. 红碱淖流域水 生态现状及保护对策. 水生态学杂志, 2012, 33(2) : 147-152.]

[24] Yang Libin, Huang Qiang, Wu Jian et al. Influence factors and prediction on area change of lake Hongjiannao. Journal of Arid Land Resources and Environment, 2014, 28(3): 74-78(in Chinese with English abstract). [杨立涁, 黄强, 武见等. 红碱淖湖泊面积变化影响因素及预测分析. 干旱区资源与环境, 2014, 28(3): 74-78.]

[25] Wang Xinsheng. A China's largest freshwater lake in a desert needs to be protected. Environment, 2010, (S2): 71-72 (in Chinese).[汪新生. 中国最大的沙漠淡水湖亟待拯救. 环境, 2010, (S2): 71-72.]

[26] Yin Lihe, Zhang Maosheng, Dong Jiaqiu. Area variation and controlling factors of Lake Hongiian, Mu Us desert, China based on remote sensing techniques. Geological Bulletin of China, 2008, 27(8) : 1151-1156(in Chinese with English abstract). [尹立河, 张茂省, 董佳秋. 基于遥感的毛乌素沙地红碱淖面积变化趋势及其影响因素分析. 地质通报, 2008, 27(8) : 1151-1156.]

[27] Zhang Baoli, Yang Lin, Ge Hong et al. The approach and measurement to alleviate water ecological environment crisis of the Hongjiannao lake. Agriculture and Technology, 2013, (4): 41-42(in Chinese). [张保利, 杨林, 葛鸿等. 缓解红碱 淖水生态环境危机途径与措施研究. 农业与技术, 2013, (4) : 41-42.]

[28] Tang Kewang, Wang Hao, Liu Chang. Preliminary study of Hongjiannao Lake's variation and ecological water demand. Journal of Natural Resources, 2003, 18(3) : 304-309(in Chinese with English abstract). [唐克旺, 王浩, 刘畅. 陕北红 碱淖湖泊变化和生态需水初步研究. 自然资源学报, 2003, 18(3) : 304-309.]

[29] Tao SL, Fang JY, Zhao X et al. Rapid loss of lakes on the Mongolian Plateau. PNAS, 2015, 112(7) : 2281-2286. 